\title{
Med.Pix
}

\section{A baby with pink cheeks}

Richard P Usatine

University of California,

Los Angeles

200 UCLA Medical

Plaza, Ste 220

Los Angeles, CA

90095-1628

Correspondence to:

Dr Usatine

rusatine@ucla.edu

Competing interests:

None declared

West I Med

2000;172:226-227

QUESTION: A 4-month-old male infant is seen because of a pink rash on his face and body. The mother says that the rash began on the child's cheeks and has spread to the body and legs. He is otherwise eating and sleeping well and has no obvious itching. The baby's diet is a cow's-milk based formula by bottle. The bowel movements and urine output have been normal. On further questioning, the mother remembered having some kind of rash as a child. She has hay fever and sometimes wheezes when she gets a cold. This is her first child, and he has had no episodes of asthma. As far as she knows, the father has never had asthma, rashes, or allergic rhinitis. There was no recent change in soaps, laundry detergent, or food.

On physical examination, the child is happy and social. Erythema and exudates are seen on the face, trunk, and popliteal fossa (figures 1, 2, and 3). The well-circumscribed, annular erythematous lesions on the back show some scaling. Erythema, exudate, and cracking of the skin are noted behind the right ear, as seen in figure 2 . There is considerable scaling and flaking on the scalp, which is not easy to see in this view.

What conditions does this infant have, and what are the appropriate treatments?

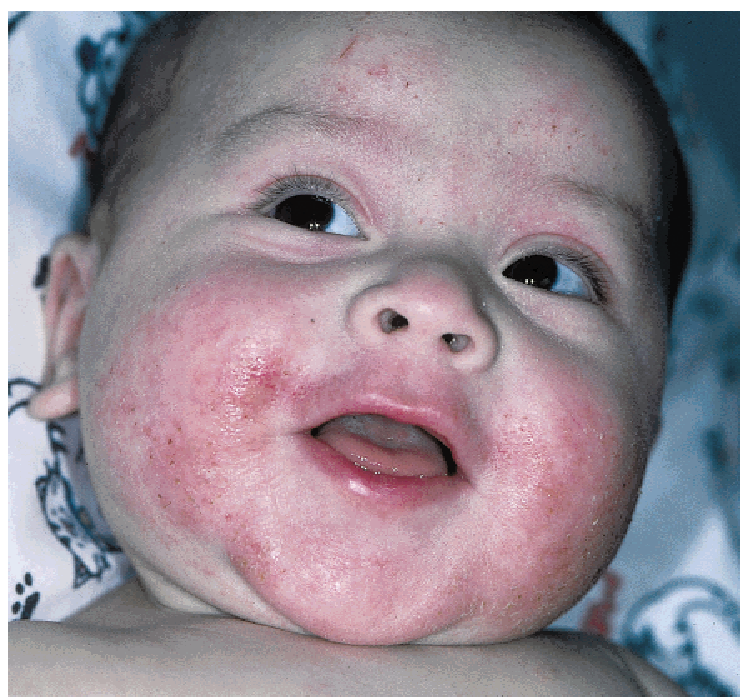

Figure 1 Face

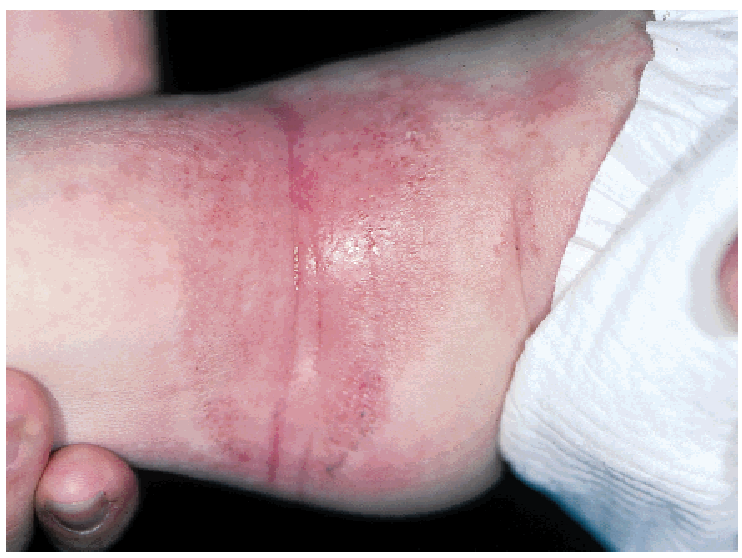

Figure 3 Popliteal fossa

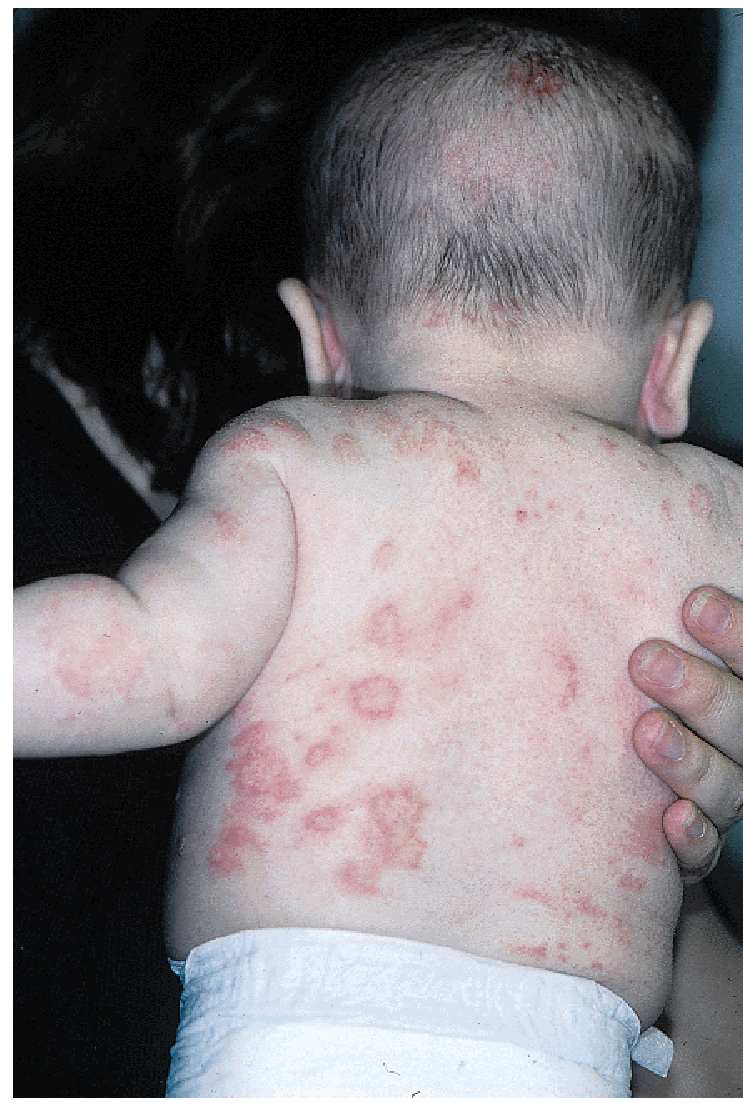

Figure 2 Trunk 
ANSWER: The infant has atopic dermatitis (atopic eczema) on the face and body. The facial involvement is the classic presentation of atopic dermatitis in this age group. ${ }^{1}$ Further supporting this diagnosis is the strong family history of atopy in the mother, who has allergic rhinitis, asthma, and a childhood history of probable atopic dermatitis. In older children and adults, atopic dermatitis is more commonly seen in areas of skin folds, including the antecubital and popliteal fossae. This infant has involvement in the popliteal fossa but not the antecubital fossa. He also has widespread involvement over his back, indicating a more severe case. The weeping of exudative fluid indicates the presence of a bacterial superinfection. In addition, this infant has cradle cap, which may be a manifestation of seborrhea or his atopic dermatitis.

\section{Treatment}

In a child with a genetic predisposition to atopic dermatitis, treatment is directed to changing the environmental factors that stimulate it. Atopic dermatitis is an inflammatory condition that may be exacerbated by topical irritants or allergens, infections, and various foods. The bacterial superinfection is most likely due to Streptococcus pyogenes and Staphylococcus aureus. The child was treated with oral cephalexin suspension twice a day for 7 days. A weak topical corticosteroid, $1 \%$ hydrocortisone cream, was recommended to be applied to the affected areas twice a day to treat the inflammatory component of the atopic dermatitis and seborrheic dermatitis.

In choosing a topical steroid, the following patient characteristics need to be considered ${ }^{2}$ : the severity and chronicity of the disorder, whether it is dry or exudative, the site involved—skin thickness, skin folds, face, genitals, hands, or feet - and the age of the patient. The steroid is chosen based on the intrinsic strength of the agent, its concentration, and the vehicle.
The least-potent steroids should be used on areas where the skin is thinnest, such as the face, genitals, and other intertriginous areas to avoid skin atrophy. Also, infants and children have greater surface area per body mass than adults. Because the risk and consequences of systemic absorption are greater, it is best to avoid the use of highpotency topical steroids in this age group.

For an infant who has considerable itching or sleep disturbance, oral diphenhydramine hydrochloride could be prescribed for use at night. Sedating antihistamines work best for pruritus. The mother was instructed to use only the mildest soaps or shampoo while bathing the infant. The physician ascertained from the mother that there was no family history of milk allergy. It was suggested that the infant be switched to a soy-based formula if the rash did not respond to the other measures.

\section{Outcome}

The infant responded well to the treatment and was taking a soy-based formula. One month later, he was seen with another exacerbation of the atopic dermatitis, and treatment was repeated, again with success. At that time, the physician discussed with the mother the long-term treatment of atopic dermatitis, including using topical emollients regularly after bathing the child and hydrocortisone occasionally for areas showing erythema and inflammation.

References

1 Correale CE, Walker C, Murphy L, Craig TJ. Atopic dermatitis: a review of diagnosis and treatment. Am Fam Physician 1999;60:1191-1198, 1209-1210.

2 Usatine R. Skin problems. In: Sloane P, Slatt L, Curtis P, Ebell M, eds: The Essentials of Family Medicine. 3rd ed. Philadelphia: Williams \& Wilkins; 1998.

\section{How to submit your medical images for publication in Med.Pix}

Do you have images (slides, photos, etc.) of compelling visual cases in clinical medicine?

If other primary care providers would find them interesting, we would like to publish them, along with a brief description of the clinical presentation and a question for the readers. The answer should provide an explanation of the clinical case along with information on differential diagnosis and treatment. The treatment section should suggest an evidence-based approach and be supported by current references. Multiple images may be submitted and interesting connections between these images may be highlighted.

High-quality slides, illustrations, and photographic prints may be mailed to:

Richard Usatine, MD; Section Editor, Med.Pix; 200 UCLA Medical Plaza, Suite 220 Los Angeles, CA 90095-1628; Fax 310-206-0181.

Written descriptions and electronic images may be submitted to: rusatine@mednet.ucla.edu.

Note: If the patient's identity is recognizable, a signed permission form should accompany the submission materials. 